\title{
Primary Health Care: Starting Point for Health Equity
}

In the 1978 Alma-Ata Declaration, developing countries threw down the gauntlet to the world's richer nations: it was time to recognize health care as a fundamental human right, implemented first and foremost by adopting comprehensive, universal primary health care models. The fiery debates came on the heels of a decade of decolonization and the Non-Aligned Movement's call for a New World Economic Order. The ensuing years, however, brought the unravelling of such an ambitious agenda, with neoliberal economic policies taking apart primary health care piece-by-piece, wrapping the remnants in "minimum" packages for specific population groups. The drive for health equity as a social policy faltered-the comprehensive, accessible, intersectoral, community-engaged, populationbased and patient-centered principles of Alma-Ata all but lost.

Not surprisingly, the health divide continued to widen, as in fact it does today, despite the race to meet the Millennium Development Goals. Yet, after the disastrous adjustment policies of the 1980s, a number of countries as far flung as Thailand, Brazil, Venezuela and New Zealand, began health care reforms generated by the original thinking behind the Alma-Ata conference. In some, the goal of "health for all" has been embedded in broader policies to address the social determinants of health, fight poverty and work with vulnerable populations to radically improve their lives. The results of such efforts have been impressive and should come as no surprise, according to the late Dr. Barbara Starfield in a seminal article published just after her death: "Primary healthcare-oriented health systems have been shown to be generally more effective in achieving better health....at lower costs than is the case for systems more oriented to disease management and specialty care. It is not often recognised that they have more equitable distribution of health as well."

In fact, as other scholars have pointed out, commitment to primary health care goes hand-in-hand with transforming the social determinants responsible for inequities. Cuba is one of the world's best examples: The World Health Report 2008: Primary Health Care Now More Than Ever, dedicated to revitalizing the communityengaged movement towards health for all, singled out the island nation for praise, while lamenting trends to hospital-centrism, commercialization and fragmentation in many health systems. The report lauded results of Cuba's community-centered, preventive, comprehensive and universal approach in the context of scarce resources. While $99 \%$ of under-five mortality occurs in developing countries, Cuba ranks with the developed nations for this indicator: just six deaths per thousand live births in 2010, on par with Canada, and lower than the rest of the Americas.

There is no secret to Cuban health outcomes: when the term "social determinants" had yet to be enshrined in global reports, over 100,000 young Cubans were volunteering in the 1961 literacy campaign, eventually teaching over 700,000 to read and write, eliminating illiteracy in a program praised by UNESCO. Early land and urban reform, the building of universal and free public education as well as health services, contributed to an environment in which health equity and comprehensive primary health care innovations could flourish. Hence, the community polyclinics emerged in the 1960s, continually adjusting their role through today, strengthening their multidisciplinary capacity; and in the 1980s came the bold move to neighborhood family doctorand-nurse offices, placing health care literally next door.
In this issue, senior editor Gorry reports on the critical contribution of family nurses to the team's continuity of care, sometimes overlooked in what has been criticized as a system too focused on physicians. Her feature also explores post-graduate nursing education and specialization (Primary Care Forward: Raising the Profile of Cuba's Nursing Profession).

Polio elimination represents one of the first great successes of active community engagement in Cuban public health policy and programs. Beldarraín provides an exciting narrative of the steps that made this possible in Poliomyelitis and its Elimination in Cuba: An Historical Overview.

Yet, of course Cuba is not immune to the fickle and often deadly global economic forces, including the US economic embargo. Pressure to dramatically improve the public health system's efficiency while increasing patient satisfaction is the aim of the health reform now under way on the island. Our reprint by Iñigez, Overview of Evolving Changes in Cuba's Health Services, provides a balanced commentary on the reforms and their potential implications, underscoring the importance of health in all policies and intersectoral action to protect health gains.

Studies conducted in primary care settings include Díaz-Perera's Contextual and Individual Influences in Diabetes and Heart Disease in Havana Primary Care Catchment Areas, a contribution to the burgeoning evidence and discourse on the importance of place as a factor in population health; as well as the article by Díaz and Espinoza, reporting on tools analyze a health problem specific to their community, aiming to devise programs to meet local health needs (Baseline Research for Action: Adolescent Alcohol Consumption in Los Palacios Municipality Cuba).

Two parting comments: experience forces us to agree with Benet when he points to the dearth of literature arising from the Cuban primary care experience (Cuban Publishing on Primary Health Care: An Inexcusable Absence). The research presented in our pages is too little, its scope too narrow to reflect such strong history and practice. We are, however, encouraged by authors such as Naranjo, the first medical student published in MEDICC Review (Diabetes Risk in a Cuban Primary Care Setting in Persons with No Known Glucose Abnormalities), who we hope represents a trend for the future.

Finally, we must address the issue of HINARI, the Health InterNetwork Access to Research Initiative, which enables researchers in developing countries full-text access to international literature otherwise financially out of reach. We were stunned to learn that Cuba was dropped from the list of countries eligible for even paid HINARI access, due to its climb higher in the Human Development Index. Cuba's progress in population health and wellbeing has been gained against great odds and sustained even in the harshest economic times. That its success should be adduced as a reason for cutting off its professionals from this resource-vital to both research and practice-is ill advised, punitive and counterproductive. We hope the $\mathrm{WHO}$ and their colleagues who made this decision can be persuaded to change it: public institutions and their professionals committed to health equity deserve better. -1 -

\section{The Editors}

